\section{LOS MITOS PREHISPÁNICOS Y LOS FENÓMENOS NATURALES EN MESOAMÉRICA}

Joel F. Audefroy ${ }^{{ }^{*}}$

\section{RESUMEN}

Este trabajo estudia el pensamiento prehispánico sobre desastres a partir de fuentes como los códices, ya sean prehispánicos o coloniales, porque hubo un interés particular de los mesoamericanos para registrar eventos celestes (cometas, eclipses solares). El objetivo principal es conocer los discursos y pensamientos de las culturas mesoamericanas relativos a los eventos desastrosos y cómo se integraron en sus prácticas religiosas. La historia mitológica del mundo mesoamericano fue muchas veces sacudida por varias destrucciones catastróficas. La relación de las culturas principalmente náhuatl y maya frente a los fenómenos naturales se hizo a través de mitos cosmogónicos y con un pensamiento cíclico del cual forman parte una serie de destrucciones y renacimientos de eventos catastróficos climáticos o geológicos. Este trabajo revisa las diferentes formas de entender e integrar los fenómenos naturales como huracanes, temblores, inundaciones y epidemias en las culturas mesoamericanas.

\section{PALABRAS CLAVES}

Mitos prehispánicos; Desastres; Huracanes; Temblores; Epidemias

\section{PREHISPANIC MYTHS AND NATURAL PHENOMENA IN MESOAMERICA}

\section{ABSTRACT}

This work studies pre-Hispanic thought on disasters from sources such as codices, whether preHispanic or colonial, because there was a particular interest of ancient Mexicans to record celestial events (comets, solar eclipses). The main objective is to know the discourses and thoughts of Mesoamerican cultures regarding disastrous events and how they were integrated into their religious practices. The mythological history of the Mesoamerican world was many times shaken by various catastrophic destructions. The relationship of the mainly Nahuatl and Mayan cultures with natural phenomena was made through cosmogonic myths and with a cyclical thought in which a series of destruction and rebirth of catastrophic climatic or geological events are part. This work reviews the different ways of understanding and integrating natural phenomena such as hurricanes, earthquakes, floods, and epidemics in Mesoamerican cultures.

\section{KEYWORDS}

Pre-Hispanic myths; Disasters; Hurricanes; Earthquake; Epidemics
1. Escuela Superior de Ingeniería y Arquitectura, Unidad Tecamachalco, Campus Estado de México, Instituto Politécnico Nacional, Ciudad de México, México.

*Autor de correspondencia: takatitakite@gmail.com

Identificador: http://revistareder.com/ handle-0719-8477-2020-o86

\section{RECIBIDO}

18 de enero de 2021

\section{ACEPTADO}

20 de febrero de 2021

\section{PUBLICADO}

1 de julio de 2021

Formato cita

Recomendada (APA):

Audefroy, J.F. (2021). Los Mitos Prehispánicos y los Fenómenos Naturales en

Mesoamérica. Revista de Estudios Latinoamericanos sobre Reducción del Riesgo de Desastres REDER, 5(2), 5-18. http://revistareder.com/ handle-0719-8477-2020-086

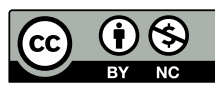

Todos los artículos publicados en REDER siguen una política de Acceso Abierto y se respaldan en una Licencia CreativeCommons Atribución-NoComercial 4.0 Internacional.

Revista de Estudios Latinoamericanos sobre Reducción del Riesgo de Desastres (REDER)

Diseño: Lupe Bezzina 


\section{INTRODUCCIÓN}

Este trabajo estudia el pensamiento prehispánico sobre desastres a partir de fuentes como los códices, prehispánicos o coloniales, porque hubo un interés particular de los antiguos habitantes de Mesoamérica para registrar eventos celestes (cometas, eclipses solares), y también los sismos. Planteamos como hipótesis que, además del pensamiento mítico, el conocimiento teórico-práctico no estaba ausente en Mesoamérica, como las adaptaciones del hábitat al clima del desierto y las zonas propensas a huracanes. El objetivo es saber cómo las diversas sociedades prehispánicas como los aztecas, y los mayas construyeron un discurso sobre los desastres a lo largo de su historia y cómo cambiaron de paradigmas a través de mitos y relatos.

Este trabajo tiene también el propósito de acercar el lector a las relaciones que existen entre los fenómenos naturales y los discursos construidos socialmente por diversas culturas prehispánicas. Esta propuesta implica interrogarse sobre el espacio del desastre y sobre sus fronteras y límites a partir de tres ejes de investigación: los eventos desastrosos históricamente situados; el desastre como espectáculo; y finalmente el desastre como construcción social.

El marco teórico de la investigación se encuentra a partir del corpus de los estudios relativos al clima y los fenómenos naturales. De hecho, existen muchos estudios sobre el pensamiento prehispánico pero muy pocos han abordado este pensamiento en relación con los desastres. Podemos citar los trabajos de Virginia García Acosta (1996, 1997, 2001, 2018); García Barrios (2014);Ortiz, F. (1947) y Albores \&, Broda (2003).

Este trabajo muestra que la historia mitológica del mundo Azteca fue muchas veces sacudida por varias destrucciones catastróficas. Según la mitología náhuatl, el mundo ha pasado por varias edades o soles regidas por dos deidades complementarias: Quetzalcóatl y Tezcatlipoca. También veremos que el huracán era un elemento central en la cosmovisión y el paradigma prehispánico. Se considera al huracán como el protagonista de los mitos cosmogónicos, de los ritos calendáricos y de la religión en las culturas mayas y aztecas. Estos mitos mayas relativos a la destrucción del mundo anterior por un diluvio, una catástrofe que permitió la creación de un nuevo orden cosmológico se encuentra en varias fuentes coloniales, imágenes y códices. Los temblores en el México prehispánico se encuentran registrados principalmente en algunos códices como el Telleriano-Remensis, y el códice Aubin.

Encontramos en los mitos de fundación, verdaderos relatos de la construcción de un pensamiento cíclico en el cual forman parte una serie de destrucciones y renacimientos de eventos catastróficos climáticos o geológicos. Estos mitos son el fundamento de una forma de pensamiento que todavía no se ha acabado, se transforma, se adapta, según las culturas y las zonas geográficas.

\section{METODOLOGÍA}

Las poblaciones prehispánicas de Mesoamérica tenían la capacidad de prever el tiempo o las amenazas hidrometeorológicas como las lluvias torrenciales y huracanes a corto o relativamente largo plazo. Para entender las ideas prehispánicas utilizamos elementos de una ciencia relativamente nueva llamada etno-climatología basada en la observación directa de los acontecimientos atmosféricos y de las acciones de las sociedades involucradas en la observación del clima. Los fenómenos como tempestades, huracanes, tormentas tropicales, relámpagos, calores sofocantes y maremotos provocan incertidumbre y temores. El miedo de caer en el caos crea respuestas humanas que consisten en construir imaginarios y mitos que son representaciones de seres sobrenaturales o divinidades localizados más allá en espacios humanizados como árboles, grutas y montañas.

Las investigaciones de Marina Golubinoff, Esther Katz y Annamaria Lammel (1997, 2008), así como las de Beatriz Albores y Johanna Broda (2003), sobre la antropología del clima, analizan la relación entre el hombre y el clima que había sido poco estudiada desde las ciencias humanas con la excepción de los trabajos de E. Le Roy-Ladurie (2007). En estas investigaciones plantean la cuestión del determinismo del clima sobre la sociedad, un tema hasta ahora debatido desde los filósofos griegos que pensaban que los factores climáticos influían en la mentalidad de las poblaciones.

Desde luego, este trabajo tiene una mirada a la vez diacrónica y sincrónica: tuvimos que considerar épocas bien definidas por su contexto cultural y en tiempos bien definidos (época prehispánica). Consideramos contextos histórico-políticos que hacían los cambios de percepción 
de los eventos y sus interpretaciones. Al interior de una época, consideramos fenómenos y pensamientos distintos en una forma sincrónica.

\section{LA CREACIÓN DEL MUNDO SEGÚN LOS AZTECAS}

Existen diversas fuentes y testimonios de las culturas mitológicas náhuatl y maya, pero son como una realidad fragmentada y solo existen algunos testimonios sobre acontecimientos desastrosos como sismos e inundaciones en los códices y anales. Nos interesa buscar los conceptos que las civilizaciones prehispánicas de Mesoamérica manejaban frente a las catástrofes. Estos conceptos dependen de su concepción del universo y de ellos mismos. Son los mitos fundadores, o mitos de origen que definen su concepción del mundo y del universo. A través de los textos escritos que revelan su pensamiento y sus ideas, así como las significaciones de las acciones como ceremonias y rituales, podemos acercarnos a una forma de pensamiento prehispánico, aunque muchas de estas fuentes fueron escritas después de la conquista española y proveniente en su mayoría del México central.

Varios autores han tratado de acercarse al pensamiento prehispánico como Alfonso Caso (2018), Mercedes de la Garza (1978), Miguel León Portilla (1958), Alfredo López Austin (2009) y Enrique Florescano (2004), pero algunos como Virginia García Acosta (2001) han intentado encontrar las ideas prehispánicas frente a los desastres. Las tradiciones y mitos prehispánicos están evocados de manera concisa en varios documentos: el principal es, sin duda, el "Codex Vaticanus A" o "Ríos", que data de mediados del siglo XVI. Se trata de una copia de un manuscrito figurativo precortesiano acompañado de valiosos comentarios del padre Pedro de los Ríos. Luego está la "Leyenda de los Soles" y los "Anales de Cuautitlán", dos textos escritos alrededor de 1558, en lengua náhuatl (azteca), por indígenas desconocidos. La "Historia de los Mexicanos por sus pinturas" y la "Histoyre du Méchique", escritas una en español y la otra en francés alrededor de 1547, con la firma de André Thévet, Christian Duverger (1983) dice que podrían ser fragmentos u obras preparatorias del perdido "Tratado" del franciscano Andrés de Olmos quien, desde 1553, había emprendido un vasto estudio de las civilizaciones indígenas en México; y la "Historia Chichimeca" de Fernando de Alva Ixtlilxóchitl (1578-1650), descendiente de la familia real de Texcoco. (Graulich, 1983).

Como muchos pueblos de América, los habitantes de Mesoamérica creían que antes de la era actual habían ocurrido varias épocas que terminaron en cataclismos. La cosmología náhuatl, a diferencia de la explicada por el libro bíblico Génesis de los cristianos, en la cual el cosmos fue creado por Dios, y es inmutable, presenta una concepción cíclica de muerte/desastre y renacimiento. Esta historia mitológica del mundo náhuatl estásacudida por destrucciones catastróficas que corresponden a una cierta visión del mundo. Así, como dice C. Duverger (1979), los Aztecas han consignado en sus creencias su percepción entrópica del universo que se manifiesta por el mito de los cuatro soles. C. Duverger (1983) nota que el orden de sucesión de los soles varía de una fuente a otra.

Así, según la mitología náhuatl, el mundo ha pasado por varias edades o soles regidas por dos deidades complementarias: Quetzalcóatl y Tezcatlipoca. Los cuatro soles anteriores al presente terminaron todos con catástrofes ocasionadas por cada uno de los cuatro elementos: tierra, viento, fuego y agua. Los cronistas antiguos pusieron los soles mesoamericanos en paralelo con los cuatro elementos de los filósofos iónicos y en particular a los cuatro elementos de Aristóteles. Nada es simple en Mesoamérica, dentro de grupos de dos elementos podemos encontrar oposición. En el grupo "celestial", el aire fue indudablemente concebido como más pesado, más en el lado terrestre, que el fuego. En cualquier caso, este fue más apreciado. Y tal vez el agua pesaba más que la tierra. Asimismo, la Tierra, Tlalteotl, está en el lado femenino oscuro, pero hay un aspecto masculino de la tierra, Tláloc. Y hay un "Sol" que también es materia, la luna. Pero también existe una complementariedad. La tierra y el agua se complementan, el agua y el fuego también. El glifo atl-tlachinolli. "agua-fuego" designa la guerra sagrada que mantiene en movimiento la máquina mundial. El hombre está hecho de carne, es decir de la tierra y del agua, pero es su aliento y su fuego interior lo que lo anima.

Según la "Historia de los Mexicanos"(1882):

El primer Sol o sol de Tierra: uno de los hijos de la suprema pareja de creadores Tezcatlipoca se había convertido en Sol. Después de 676 años, o sea 13 ciclos de 52 años, su hermano Quetzalcóatl lo golpeó con un palo. Tezcatlipoca cayó al agua, se transformó en jaguar y 
devoró a los gigantes que habitan la tierra. Estos gigantes arrancaron árboles y comieron borlas.

El segundo Sol o sol del Viento: Quetzalcóatl sucedió a Tezcatlipoca como Sol. El mundo estaba poblado por hombres corrientes, macehuales, que no comían más que mízquitl (acacia, mezquite). Después de 676 años, Tezcatlipoca creó un viento terrible que arrastró a Quetzalcóatl y a todos los hombres. Algunos de ellos se convirtieron en simios.

El tercer Sol o sol de Fuego: Tláloc, dios de la tierra y la lluvia, fue Sol durante 364 años (7 ciclos de 52años). Los hombres comieron acicintli (algo muy semejante al maíz). Quetzalcóatl al fin hizo que cayera del cielo una lluvia de fuego.

El cuarto Sol o sol de Agua: Quetzalcóatl instaló a la diosa del agua Chalchiuhtlicue como el Sol durante 312 años ( 6 ciclos de 52 años). Los hombres comieron cincocopi. Una inundación convirtió a los hombres en peces y los cielos cayeron sobre la tierra ${ }^{1}$.

El quinto sol o sol del Movimiento: La época actual terminará, cuando Tezcatlipoca "robe" el Sol. Quetzalcóatl lo domina. Otras fuentes hablan de destrucción por hambrunas y terremotos, un colapso del cielo y el descenso de monstruos nocturnos, los Tzitzimime, que devorarán a los hombres.

Es difícil saber, como lo dice Mercedes de la Garza (1978), si las destrucciones fueron totales o parciales del mundo entero o sólo de los hombres. Las fuentes no lo precisan. Es interesante aquí observar que, a través de estos mitos, el mundo está recreado a partir de catástrofes en las cuales alguna pareja sobrevivió. Mercedes de la Garza se inclina por la hipótesis siguiente: "las edades segunda, tercera y cuarta se refieren a las transformaciones dentro del mismo mundo ordenado en la primera; que este mundo se destruyó totalmente por agua al final de la cuarta edad, y que el mundo actual es el segundo formado por dioses". El códice azteca conservado en la Biblioteca Vaticana (Codex Vaticanus 3738) atribuye a cada época una duración de cuatro a cinco mil años, lo que da un total entre 16,000 y 20,000 años para las cuatro eras (Covarrubias, 1961). Como lo decía C. Duverger, las fuentes no coinciden en la duración de las épocas.

El orden de los soles, analizado por Graulich (1983) es particularmente interesante. En cada época o sol, existe una alternancia entre Tezcatlipoca y Quetzalcóatl. Cuando uno es Sol, es su adversario quien destruye el mundo. Esto, sin embargo, no es el caso en la "Historia de los Mexicanos". En la primera y la cuarta edad, es el Sol destronado el que se convierte en agente de destrucción. Al final del sol de Tierra, Tezcatlipoca se transformó en jaguar y devoró a los hombres. Podemos admitir que, al mismo tiempo, fue Quetzalcóatl quien provocó el diluvio que acabó con el Cuarto Sol (ver Tabla 1).

\begin{tabular}{llll} 
Nombre del sol & Nombre del dios & Efectos & Tipo de destrucción \\
\hline $\begin{array}{l}\text { Sol de Tierra } \\
\text { (Nahui Ocelotl) }\end{array}$ & Tezcatlipoca es sol & $\begin{array}{l}\text { Tezcatlipoca se vuelve } \\
\text { Jaguar }\end{array}$ & $\begin{array}{l}\text { Caída del Cielo, temblor, } \\
\text { llegada de jaguares. }\end{array}$ \\
\hline $\begin{array}{l}\text { Sol de viento } \\
\text { (Nahui Ehécatl) }\end{array}$ & Quetzalcóatl es sol & $\begin{array}{l}\text { Tezcatlipocaprovoca } \\
\text { vientos }\end{array}$ & $\begin{array}{l}\text { Vientos destruyen. } \\
\text { Huracán. }\end{array}$ \\
\hline $\begin{array}{l}\text { Sol de fuego } \\
\text { (Nahui Quiauitl) }\end{array}$ & Tezcatlipoca es sol & $\begin{array}{l}\text { Quetzalcóatlproduce } \\
\text { fuego }\end{array}$ & $\begin{array}{l}\text { Fuego es agente de } \\
\text { destrucción. } \\
\text { Lluvia de fuego. }\end{array}$ \\
\hline $\begin{array}{l}\text { Sol de agua } \\
\text { (Nahui Atl) }\end{array}$ & Quetzalcóatl es sol & $\begin{array}{l}\text { Quetzalcóatlprovoca un } \\
\text { diluvio }\end{array}$ & $\begin{array}{l}\text { El agua es agente de } \\
\text { destrucción }\end{array}$ \\
\hline $\begin{array}{l}\text { Sol de movimiento } \\
\text { Ollintonatiuh }\end{array}$ & Tonatiuh es sol & 4 Ollín (4 Movimiento) & Temblor \\
\hline
\end{tabular}

Tabla 1. Alternancia de los Soles en 5 épocas

Fuente: Autor, 2021, adaptado de Michel Graulich, 1983 y Florescano, 2009.

Según el "Histoyre de Méchique" (1905), los hombres se ahogaron durante el diluvio por los pecados que habían cometido contra los dioses". El padre Ríos también sugiere que el diluvio fue causado por "pecados "(Codex Telleriano-Remensis 1964-1967: 217, pl. 20). Los cataclismos tenían el efecto, en todo caso, de purificar a los hombres. Parece obvio que el padre Ríos asimiló el diluvio mexica al diluvio del Antiguo Testamento, dándole una causa similar a la causa bíblica.

1. Todas las fuentes confirman el tema del diluvio. La "Leyenda de los Soles" también habla del colapso del cielo y menciona, junto con el "Histoyre du Méchique", los "Anales de Cuautitlán" y el "Vaticanus A" la transmutación en pez. 
En el campo que nos interesa, no sólo el agua de la inundación, sino también el fuego, la tierra y el aire constituyeron agentes de purificación. La tierra también se estaba purificando. Uno de los ritos más frecuentes era el de humillarse comiendo tierra (tlalcualiztli). Diego Durán dijo que, en determinadas circunstancias, se pedía al mismo tiempo el perdón de sus culpas(León-Portilla, 1958).

Como lo observa Mercedes de la Garza (1978), en las distintas fuentes, los hombres fueron convertidos en animales en cada una de las catástrofes. En el Códice Vaticanus-Ríos, de cada catástrofe se salvó una pareja humana que dio continuidad a los hombres de la etapa siguiente. Por ejemplo, en la primera, Ometeotl creó a Oxomoco y a Cipactónal quienes se multiplicaron poblando el mundo. Luego vino un diluvio y los hombres se volvieron peces. En la segunda edad, que terminó por viento, los hombres se volvieron monos. La tercera edad terminó por fuego, pero escapó una pareja dentro de una gruta. En la cuarta edad vivieron los hombres que provienen de esta pareja y hubo viento y lluvia de sangre.

Este mito cosmogónico de los cuatro Soles es uno de los más complejos y profundos de Mesoamérica y va más allá de la memoria cataclísmica, traducido en una simbología elaborada, su entendimiento es extremadamente lúcido sobre la inestabilidad del mundo en el cual vivían los aztecas (Duverger,1979). Se trata también de un proceso de regeneración y purificación de los hombres con la ayuda de los dioses. Los cuatro elementos son los agentes de purificación, el fuego, el diluvio y el viento son elementos perturbadores que tienen profundos orígenes en la climatología mesoamericana. Una "lluvia de fuego" hace pensar en los volcanes ya que Mesoamérica es tierra de volcanes. La erupción del volcán Xitle en el año 76 d.C.(según Fernando de Alva Ixtlilxóchitl), que produjo $80 \mathrm{~km} 2$ de lava en el sur de la ciudad azteca ha dejado huellas en la memoria de los habitantes y fue la causa del abandono de Cuicuilco.El viento y el diluvio hacen pensar en los huracanes que traen agua y viento cada año. E. Florescano (2004) menciona que el dios del viento, Ehécatl, aparece a finales de la época clásica y en el Posclásico, vinculado con los dioses del viento de la región del Golfo de México, propensa a huracanes. Finalmente, el quinto sol, el del movimiento está relacionado con los temblores que, como lo demostró García Acosta (2001, 2018) fueron registrados desde la época prehispánica a través de glifos (tlalollin) en los códices. Por ejemplo, en el Códice Telleriano Remensis fueron registrados 10 temblores ocurridos entre el año 7 pedernal (1460) y el año 6 casa (1537)

Los mitos de creación estaban construidos a partir de grandes catástrofes en las que la humanidad se hundía periódicamente y el año 1519 coincidió justamente con el término de una era (Lafaye, 1995).Es interesante observar con García Acosta (2018) que "en las sociedades mesoamericanas, los temblores no eran reconocidos como obra de justicia divina, no existía una concepción fatalista al considerarse la posibilidad de poder dialogar con las deidades responsables de su ocurrencia".La integración de los fenómenos geológicos y climáticos muestra por parte de las sociedades mesoamericanas, una voluntad de asimilar fenómenos que no podían entenderse de otra forma ya que no disponían de herramientas suficientes. Sin embargo, los observatorios construidos en los centros ceremoniales atestiguan de una voluntad de captar el movimiento de las estrellas y otros fenómenos celestes como cometas y eclipses que se consideraban agüeros funestos de futuras catástrofes. Estos fenómenos fueron registrados en el Códice Telleriano Remensis: un eclipse solar en 1507 (año2 caña) y cometas en 1533 (año 2 casa) y 1537 (año 6 casa).

\section{HURACANES, MITOS Y REPRESENTACIONES}

El huracán era un elemento central en la cosmovisión y el paradigma prehispánico. Varios autores concuerdan en esta afirmación: Ortiz, 1947; De la Garza, 1978, Konrad, 2003, Katz y Lammel, 2008. Lo que es verdaderamente sorprendente es que, a pesar de la conquista española, todavía, en varios trabajos antropológicos contemporáneos, se encuentran mitos y símbolos que son la continuidad de los mitos prehispánicos.

Sabemos poco de los huracanes ocurridos durante el clásico ( 250 a 900 d.C.) o el posclásico (900 d.C. al 1521 d.C.) mesoamericano. Existen algunas fuentes como Diego De Landa (15241579) que reporta un huracán en 1464 en su famosa Relación de las cosas de Yucatán. Gonzalo Fernández de Oviedo (1478-1557) describe en su Historia general y natural de las Indias, dos huracanes que azotaron la isla de Hispañola el 3 de agosto de 1508 y el 29 de julio de 1509 con un impacto particularmente impresionante en los bosques tropicales. Existen además numerosas 
referencias a los dioses de la lluvia en los códices mayas (Dresde, Madrid, París) que se refieren principalmente a los huracanes.

La palabra huracán tiene su origen en un término ancestral que designaba a una deidad del panteón prehispánico. En el Popol Vuh (del k'iche' popol wuj: 'libro del consejo" o "libro de la comunidad") se encuentra este término:

Entonces dispusieron la creación y crecimiento de los árboles y los bejucos y el nacimiento de la vida y la claridad en acción del hombre. Se dispuso así en las tinieblas y en la noche por el Corazón del Cielo, que se llama Huracán. El primero se llama Caculhá Huracán. El segundo es Chipi-Caculhá. El tercero es Raxa-Caculhá. Y estos tres son el Corazón del Cielo.

El arqueólogo cubano Fernando Ortiz (1947) fue el primero en interpretar los fragmentos de vasija, códices y obras arqueológicas con la representación del Hurakán. Los antiguos pobladores caribeños y de la costa del Golfo de México compartieron elementos de las culturas circuncaribes y muchos de estos elementos se difundieron en toda Mesoamérica en el momento que se estaban conformando las diferentes religiones, de tal forma que es posible ahora reconocer la presencia de Hurakán en varios dioses: en los mayas peninsulares Hurakán se identifica con Chaac, el dios de la lluvia; en el Altiplano mexicano Chaac se convierte en Tlaloc y en los totonacas de Veracruz será Tajín (Cuevas y Navarrete, 2006).

Se considera al huracán como el protagonista de los mitos cosmogónicos, de los ritos calendáricos y de la religión tanto en la cultura maya como azteca, en todas partes donde hubo tornados, tolvaneras, torbellinos y trombas, así los mitos se extendieron por el norte y por el sur de América. Según Diego de Landa (1966), las dos fiestas anuales consagradas por los mayas a Kukulkán, su dios del viento, eran en el $6^{\circ}$ mes (octubre noviembre) y en el $16^{\circ}$ mes (mayo, entrada de las estaciones de lluvias).

Como las poblaciones prehispánicas lo habían observado, los huracanes no cruzan fácilmente las regiones montañosas y se disipan al entrar en tierras continentales. Además, el huracán es siempre más violento en el mar donde los vientos experimentan una fricción menor que en la tierra. Ortiz (1947) plantea la hipótesis que, por estas particularidades, los mayas continentales pudieron imaginar que una espiral sobre una figura de montaña era muy adecuada para el signo del viento. La espiral es así un símbolo meteórico que originariamente significa el viento y por eso se une a otros sentidos equivalentes o complementarios como la serpiente que es una síntesis de espirales vivas y también es un símbolo del viento y biomorfización del dios del aire.

Según Ortiz, el remolino aéreo de la tromba, y el tornado fueron el origen del símbolo prototípico de la espiral, y luego por analogías morfológicas, la sigma, la onda, la nube, la lluvia, la serpiente, y todos los fenómenos naturales relacionados significaron lo mismo: el remolino aéreo y acuático de la tromba, el tornado, el huracán y la nube tempestuosa y portadora de lluvias (ver Figura 1).

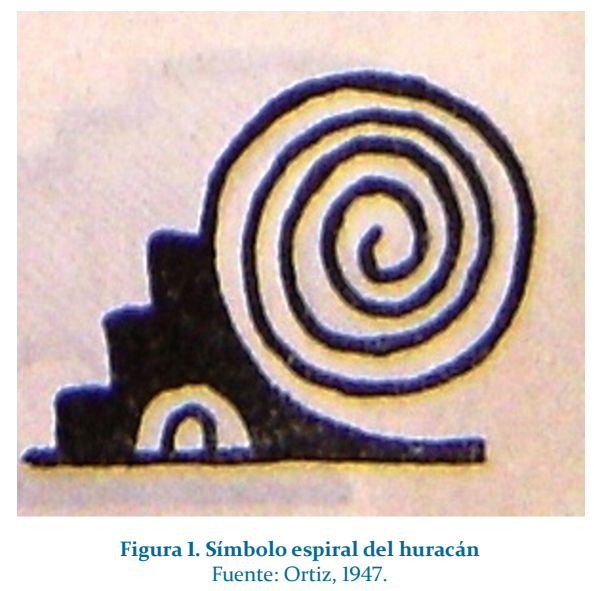


La relación entre el imaginario cosmológico de los mayas y la variabilidad climática se entiende si consideramos que en las tierras bajas de Guatemala y en las zonas calcáreas de la península de Yucatán donde no existen ríos y solo hay un suelo kárstico, la lluvia era de máxima importancia pues solo llueve en una época del año (de junio a noviembre) y así no es extraño que sus dioses principales fuesen asociados al trueno, el rayo, la lluvia como Chaac, el dios del agua, las lluvias y tempestades. Mientras Kukulkán, dios del viento y del huracán es también la serpiente emplumada de los mayas: Ku quiere decir dios o divinidad; Kul, muy o mucho y Kan, culebra, lo que significa "dios fuerte culebra". La serpiente es una espiral zoomorfa, es otro símbolo, como la espiral misma, del huracán.

H. Konrad (2003) emite la hipótesis de que la adaptación efectiva a los efectos ecológicos de los huracanes repercutió en el éxito o el fracaso de las estrategias de subsistencia en la península. Los impactos son significativos en los bosques y en el hábitat. Según él, el impacto ecológico se puede dividir en cuatro categorías principales:

- Daños por marejada ciclónica a lo largo de las costas,

- destrucción del viento, que afecta a los animales, la fauna y los seres humanos,

- altos niveles de agua y actividad de inundaciones como resultado de lluvias extremas, que se han registrado, e

- incendios forestales posteriores a huracanes.

Sin embargo, había un proceso de adaptación a sequías por medio de chultunes (pozos de recuperación de agua de lluvia), adaptación del hábitat a vientos huracanados, por medio de varios conceptos arquitectónicos. La abundancia de casas con paredes y techos redondeados sería una adaptación positiva ya que estas estructuras resisten mejor los vientos fuertes que las de paredes o techos cuadrados. Y, de hecho, el conocimiento de los mayas de su medio ambiente no está suficientemente reconocido y era más complejo que lo que se imagina. Había también técnicas de silvicultura y estrategias de subsistencia para enfrentar la variabilidad climática.

\section{EL MITO DEL DILUVIO EN LOS MAYAS DE YUCATÁN}

Durante los periodos posclásico y colonial se encuentran distintas versiones sobre la existencia de un diluvio que destruyó el mundo anterior y permitió la creación de un nuevo orden cosmológico.

Una de las principales fuentes de la mitología maya es el Popol Vuh, (del k'iche' popol wuj: 'libro del consejo' o 'libro de la comunidad'), es una recopilación de narraciones míticas, legendarias e históricas del pueblo k'iche', uno de los 20 grupos etnolinguísticos del pueblo maya guatemalteco. Está formado por una serie de relatos que tratan de explicar el origen del mundo y de la civilización maya y de diversos fenómenos que ocurren en la naturaleza.

Se supone que el libro fue escrito hacia 1550 por un indígena, que después de aprender a leer y escribir en latín, transcribió el relato oral de un anciano. Fue el manuscrito del padre Ximénez de Chichicastenango que contiene el texto más antiguo del Popol Vuh, escrito en forma paralela en K'iche y en español.

La parte del relato de creación se resume así2: Los dioses crean el mundo, crean los valles y las montañas. Luego, los dioses crean a los animales, pero ya que no los alaban, los condenan a comerse unos a otros. Seguido, los dioses crean a los seres de barro, los cuales son frágiles e inestables y no logran alabarlos. Frente a este fracaso, los dioses crean a los primeros seres humanos de madera, estos son imperfectos y carentes de sentimientos, y esta primera generación no fue satisfactoria, fueron depuestos por los dioses quienes decidieron destruirlos para retomar su obra de mejor manera. Así organizaron un gran diluvio, fue el diluvio Maya-Quiché, un gran cataclismo que precede el relámpago de tormentas "tuvieron hijos los muñecos de palo; pero no tenían alma, ni entendimiento, no se acordaban de su Creador [...] ya no se acordaban del Corazón del Cielo y por eso cayeron en desgracia [...] en seguida fueron aniquilados, destruidos y [...] recibieron la muerte. Una inundación fue producida por Corazón del Cielo (Uk'u'x Kaj), un gran diluvio se formó, que cayó sobre las cabezas de los muñecos de palo. "Por esto se oscureció la faz de la tierra, comenzó la lluvia oscura, la lluvia de día, la lluvia de noche". Vucub Caquix sobrevivió a la inundación y entró en conflicto con Hunahpú e Ixbalanqué, lograron matar a Vucub Caquix y su esposa Chimalmat y vencieron a sus hijos Zipacna y Caprakan. Entonces los creadores reanudaron su trabajo, se formaron los primeros cuatro hombres y tenían la apariencia humana.

2. En base a la traducción de Adrián Recinos, 1968. 
Existe otra fuente, el Chilam Balam de Chumayel (1973) que presenta otra versión de la creación del mundo: "La narrativa comienza con un cataclismo producido por un lagarto que vomita el fluido que anega la tierra. A continuación, los propios dioses decapitan al reptil y se detiene la inundación. Posteriormente, el cuerpo del reptil cae sobre la tierra, y sobre sus cuatro esquinas se colocan los cuatro árboles del mundo para levantar y sujetar el cielo caído" según García Barrios, (2014) que también afirma que "imágenes del Preclásico Tardío (400 a.C.-250 d.C.), así como textos posclásicos y coloniales también coinciden en indicar que, después de esta inundación, se colocan cuatro árboles en las cuatro esquinas del mundo para levantar el cielo". Otra secuencia del mito menciona que "un ser sobrenatural llamado Uuc Cheknal viene de la séptima capa de la tierra y pisa la espalda decapitada de Itzam Cab Ain, nombre que recibe durante el Posclásico el lagarto de la inundación de los monumentos clásicos". En esta parte del mito, la decapitación significa muerte y fin del caos; la acción de pisar la espalda decapitada, significa la reorganización del nuevo mundo.

Así, los mayas prehispánicos, cuando accedían al trono, se asimilaban a los héroes míticos victoriosos que decapitaban al lagarto que había producido la inundación (o caos), fundadores del nuevo mundo. Las ceremonias de entronización de los dirigentes mayas eran como una recreación mítica de la construcción del mundo, una metáfora del ordenamiento y fundación del nuevo reinado. La acción de pisar dejaba huellas en el territorio controlado. Se puede ver la representación de esta toma de poder en el Templo XIX de Palenque ${ }^{3}$.

Según López Austin (2009), el tiempo mítico de los mayas es una especie de tiempo simultaneo, donde no existe ni pasado, ni presente, ni futuro, pero este tiempo cambia después de la inundación, el mundo está ordenado y el cielo sustentado por los cuatro árboles cósmicos, los Bacabes (B'aah Kaab'), y se funda un nuevo mundo. Esta concepción del tiempo mítico y el histórico no ha cambiado hasta nuestros días en la mayoría de los pueblos mayas y en los rituales todavía existe una sincronía entre los dos tiempos mítico y el histórico.

Velásquez García (2006), recuerda que "un importante pasaje, contenido simultáneamente en los libros de Chilam Balam de Tizimín y Maní, refiere que el diluvio fue precedido por un eclipse y provocado por un lagarto pluvial y celeste, cuya cabeza fue cortada a fin de construir con sus restos desmembrados el nuevo orden cosmológico". Este pasaje confirma el Chilam Balam de Chumayel "en el sentido de que B'olon ti' K'uh y las fuerzas chthonianas del Inframundo fueron el agente que derribó los cielos, pero también el motor de la creación presente, pues al decapitar al caimán celeste hicieron posible la construcción de un nuevo mundo".

El franciscano Diego de Landa, en su Relación de las cosas de Yucatán (1966:cap. XXXIV), menciona el mismo mito, pero con su interpretación católica monoteísta:

Entre la muchedumbre de dioses que esta gente adoraba, había cuatro, llamados Bacab cada uno de ellos. Estos eran cuatro hermanos a los cuales puso dios, cuando creó el mundo, en las cuatro partes de él, sustentando el cielo para que no se cayese. También decian de estos Bacabes, que escaparon cuando el mundo fue destruido por el diluvio. Ponen a cada uno de estos otros nombres señalando con ellos la parte del mundo en donde dios los había puesto.

Así, estos mitos mayas relativos a la destrucción del mundo anterior por un diluvio, una catástrofe que permitió la creación de un nuevo orden cosmológico se encuentran en varias fuentes coloniales, imágenes y códices como el de Dresde y Pérez (Chilam Balam de Maní).

Este mito de la gran inundación y de la decapitación del lagarto, está documentado desde el siglo VIII en Palenque y hasta el siglo XVIII en los libros de Chilam Balam, pero, como otros mitos, tuvo variaciones importantes a lo largo de diez siglos. En la versión maya clásica el líquido vertido por el lagarto es sangre, mientras que en el Códice de Dresde y otras fuentes escritas es agua.

\section{LOS TEMBLORES EN EL MÉXICO PREHISPÁNICO}

Cuando los temblores no son recordados, se transforman en dioses o mitos que es una forma de recordar. La memoria histórica en los tiempos prehispánicos era diferente de la memoria actual, los acontecimientos se grababan en piedra (estelas o murales), pinturas murales, en códices o se trasmitían de manera oral. La interpretación de los temblores era muy distinta según las culturas. 
Los indígenas del suroeste de los Estados Unidos asimilaban los terremotos a las sacudidas de una gran serpiente o dragón subterráneo. Las poblaciones originarias de América del Norte consideraban los sismos como un efecto del movimiento de animales subterráneos y distintos según la magnitud: una tortuga marina, una ballena o un cerdo (Ferradas, 2015).

Los caribes antillanos consideraban el terremoto como una señal de la tierra para que aquellos bailaran por su propia salud, y entonces danzaban cuatro días y otras tantas noches, en forma litúrgica con grandes ornamentos y atavíos, llevando collares, brazaletes, cinturones y tobilleras llenas de pequeñas conchas que entrechocaban con los movimientos del baile, mientras los indígenas sonaban maracas y hacían un monótono acompañamiento (Ortiz, 1947). En estas poblaciones los temblores no eran una amenaza ni un castigo, eran parte de la vida.

En Mesoamérica, los temblores estaban relacionados con los mitos mayas del Chilam Balam de Chumayel, con los cuatro Bacabes:

Los temblores de tierra no eran una casualidad peculiar del espíritu que se adoraba en el subterráneo de Tehuantepec, sino de todos los dioses sostenedores del cielo. Es decir, de los cuatro dioses de los cuatro vientos. Los temblores y terremotos que en la tierra había, los atribuían a que los dioses que tenían en peso el mundo, se cansaban y entonces se mudaban y que aquella era la causa de los temblores. La diosa Tierra, uno de ellos, tenía el título de Corazón de la Tierra en su advocación de Toci, y se lo daban "porque cuando quería hacía temblar la tierra (Ortiz, 1947:67).

Así, los mames de Rabinal, en Guatemala, tenían la creencia de que el mundo estaba sostenido sobre los hombros de cuatro gigantes (los Bacabes) que, cuando se cansan de sostener al mundo, cambian la carga al otro hombro y es cuando se producen los temblores, o sea el KabRakan, el dios quiché de los terremotos y volcanes, el de las conmociones sísmicas (Hermesse, 2007).

En la cosmogonía mexica se veía a los temblores como el resultado de que la tierra tropiece con el sol (Silva Ortiz,2019). En Oaxaca, en tierra zapoteca temblor se dice Xoo y el dios de los temblores es Pitao xoo; en la mixteca alta, "está temblando la tierra", se dice tnna ñuu.

En 1475 (9 caña), el gran tlatoani de Tenochtitlán llamado Axayacatl, el padre de Moctezuma II, pensaba que el temblor de este año era un presagio, de hecho, las chinampas se abrieron, casas, teocalis y palacios fueron dañados, hay cerros que se desmoronaron y el lago de Texcoco se movió. La intensidad parece haber sido considerable, y García Acosta (2001) encontró dos fuentes que mencionan este acontecimiento: Chimalpahin (1579-1645) para la zona de ChalcoAmecameca y el franciscano Juan de Torquemada (1557/1565-1624) para el Valle de México quien nos dice que después del temblor el rey Axayacatl venció a los de Malacatepec y Coatepec. Así parece que este temblor fue un buen presagio. En el caso del Templo Mayor en Tenochtitlán, los códices indican que la fase IVB está relacionada con este sismo de 1475 , que ocasionó su destrucción total. La fase VII de este Templo Mayor, fue la que encontraron los españoles durante la conquista y que destruyeron por motivos religiosos, para luego reutilizar el material en los edificios coloniales (Rojas Aceval, 1991).

Los temblores en el México prehispánico se encuentran registrados principalmente en algunos códices como el Telleriano-Remensis, y el códice Aubin (en prosa náhuatl) y anales. Estos códices y anales fueron escritos algunos antes y otros después de la conquista, por indígenas. De hecho, muchos de los códices escritos antes de la conquista fueron destruidos por los misioneros españoles que quisieron hacer desaparecer los testimonios de las antiguas creencias y culturas de los indígenas. Los nahuas, mixtecos y mayas son las principales culturas que relataron acontecimientos en códices y anales.Otra fuente de los sismos, son los cronistas indígenas y españoles: Fernando de Alva Ixtlilxóchitl, Juan de Torquemada, autor de la Monarquía Indiana (1615) y Chimalpahin, cronista indígena perteneciente a la nobleza Chalca.

Lo que caracteriza la representación de los sismos en los códices es la forma de glifos asociados: el glifo ollín (movimiento) está asociado a capas de tierra (tlalli) y de acuerdo a interpretaciones arqueológicas, se refiere a movimientos telúricos (ver Figura 2). Este signo se repite hasta 3 veces, cuando relatan que tembló en 3 ocasiones y están graficadas sobre de una a cinco capas de tierra (ver Figura 2). 


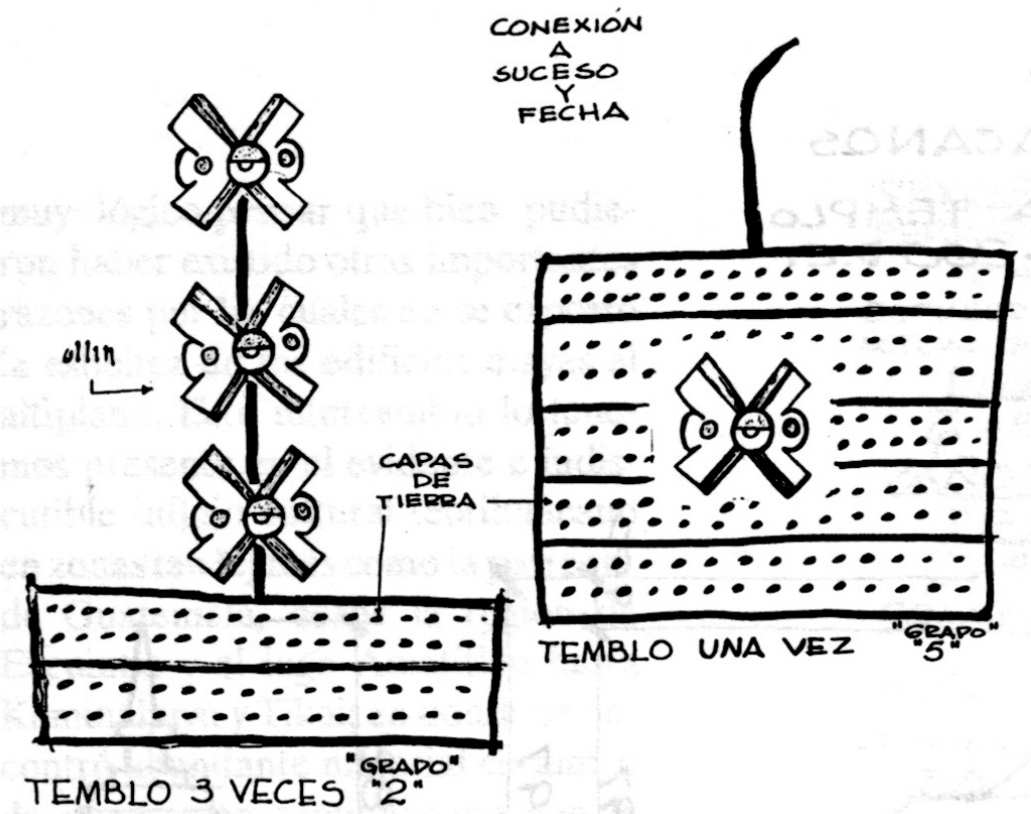

$$
\text { , }
$$

Figura 2. Glifo ollín asociado con las capas de tierra Fuente: Rojas Aceval, 1991.

Según la interpretación de Rojas Aceval (1991) y García Acosta (2001), el número de capas de tierra (tlalli) podría significar una forma indígena de evaluar la magnitud sísmica. No sabemos si las capas de tierra están representadas en corte o en plano como si fueran unos sillones de cultivo de maíz. En los códices existen elementos en plano y otro en cortes. Lo interesante también es observar la posición de ollín respecto a las capas de tierra (tlalli), como lo muestra la Figura 3:
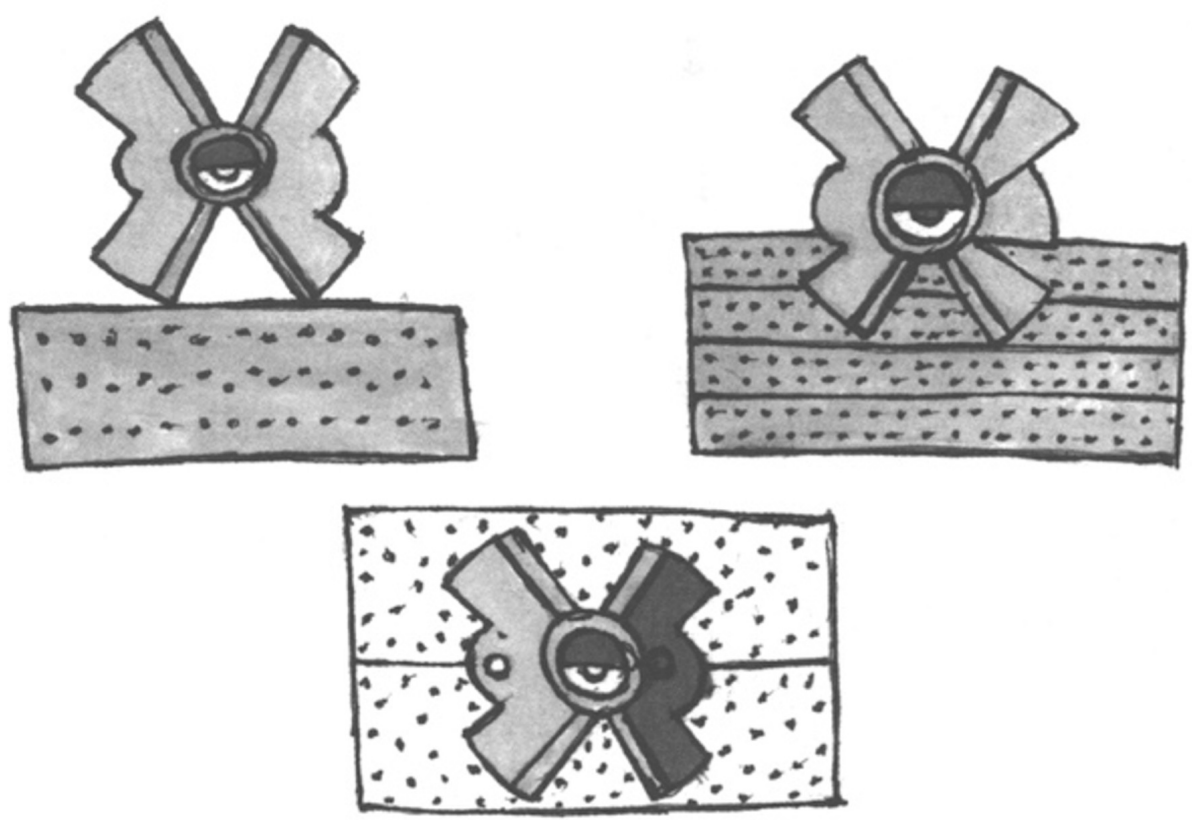

Figura 3. Posición de ollín en relación con las capas de tierra Fuente: García Acosta, 2001.

No se tienen hasta ahora explicaciones de la posición de ollín, faltarían investigaciones más profundas para determinar el sentido de estas representaciones de temblores. 
Los constructores mesoamericanos estaban perfectamente conscientes de las amenazas sísmicas. Si comparamos la arquitectura de los templos en zonas sísmicas y en zonas asísmicas podemos observar lo siguiente: en Tikal, Guatemala, zona asísmica, el basamento tronco-piramidal del templo V mide 59x46m con una altura de 62 metros. La pirámide del Sol en Teotihuacán, zona sísmica, el basamento mide 220 x 220m con una altura de 72m. Rojas Aceval (1991) afirma que la razón por la cual no se exportó la esbeltez de los edificios mayas al altiplano, pudiera ser el conocimiento empírico que tenían los constructores mesoamericanos en cuanto a la ocurrencia periódica de los sismos que ocasionaron severos daños estructurales a los edificios. Así, estaban conscientes que la edificación en el altiplano central mesoamericano con las proporciones formales similares a las del templo $\mathrm{V}$ de Tikal sufriría severos daños estructurales.

Es interesante observar esta doble concepción frente a los sismos, la primera que podríamos llamar mítica-mágica, y la otra racional cohabitaban en el pensamiento prehispánico. García Acosta (2001) emite la hipótesis según la cual, por esta concepción del mundo se deriva la preocupación de los indígenas náhuatl prehispánicos de registrar estos eventos y de presentarlos en asociación con otros fenómenos naturales considerados como premonitorios, tales como heladas, nevadas, vulcanismo, eclipses o cometas. García Acosta encontró que en 1490 tembló y apareció un fantasma que llamaron Toyohualytohua, anunciando alguna muerte. Esta concepción mágica frente a los fenómenos naturales es mencionada por Fray Bernardino de Sahagún (1499-1590), lo que muestra que las dos concepciones cohabitaban:

Cuando temblaba la tierra rociaban con agua todas sus alhajas, tomando el agua en la boca y soplándola sobre ellas, y también por los postes y umbrales de las puertas y de la casa; decían que si no lo hacian esto que el temblor llevaría aquellas casas consigo; y los que no hacían esto eran reprendidos por los otros; y luego que comenzaba a temblar la tierra comenzaban a dar gritos, dándose con las manos en las bocas, para que todos advirtiesen que temblaba la tierra (Sahagún, 1979: 281, citado por García Acosta, 2001).

El sistema de los aztecas, gritando con las manos en las bocas, es un ancestro del sistema de alerta temprana de la Ciudad de México. Sahagún menciona otra superstición:

Cuando temblaba la tierra, luego tomaban a sus niños con ambas manos por las sienes, y los levantaban en alto; decían que si no hacian aquello que no crecerían y que llevaría el temblor consigo (Sahagún, 1979: 281, citado por García Acosta, 2001).

Las informaciones múltiples y diversas que tenemos sobre el pensamiento náhuatl sobre los sismos se deben a la multiplicidad de fuentes, algunas históricas, otras míticas, y, como dice $\mathrm{C}$. Duverger (1983), la interpenetración sistemática del mito y de la historia enraíza profundamente esta última en el campo de los subjetivo, la mitología es el vector de la ideología. Por lo tanto, si logramos por un lado tener algunos mitos narrados, en varias versiones, a veces contradictorias, también encontramos anécdotas sobre las actitudes de los aztecas frente a los sismos. Mitos, creencias y decisiones racionales cohabitan en el pensamiento prehispánico. Es un poco lo que queríamos demostrar: no existe en el pensamiento náhuatl sobre los desastres un pensamiento unívoco, sino más bien un corpus de actitudes e ideas, la mayoría empíricas frente a movimientos de tierra.

\section{LAS EPIDEMIAS Y OTROS MALES EN LA ERA PREHISPÁNICA}

En la época prehispánica las poblaciones de Mesoamérica habían deificado en los mitos maya monos y mosquitos. Parece ser que antes del descubrimiento de las Américas se conocía ya la fiebre amarilla: entre los náhuatl con el nombre de cocolitzle; entre los mayas de Yucatán con el de xekik (vómito de sangre) y entre los caribes con el de poulicantina. En los códices mayas, en la parte correspondiente a los recetarios de los indígenas, se hacían referencias sobre la "medicina para el vómito de sangre", y en otra parte se señalaba: "medicina del vómito de sangre para personas que la arrojan no propiamente encarnada, que no parece verdadera sangre, sino como un líquido mezclado de hollín".

Ahora sabemos que el mosquito Aedes aegypti y ciertos monos como el aullador y el mono araña, son responsables de la proliferación de la fiebre amarilla. El virus de la fiebre amarilla pertenece al género Flavivirus (Familia Flaviviridae), se caracteriza por ser una fiebre hemorrágica 
viral, pansistémica, que ocasiona daño hepático, renal, cardiaco, shock y es de alta letalidad (Cárdenas-Marrufo, 2017).

Los Códices Mayas Chilam Balam de Chumayel y de Tizimin, evidencian que la población ya había sido afectada por la epidemia de fiebre amarilla. El simio, en los mitos mayas ha sido creado por los dioses y se salvó de un diluvio con trepar árboles. Esto nos revela que los mayas reconocieron en los monos y en los mosquitos a los agentes de esta enfermedad. En el libro del Popol Vuh se puede reconocer la antigüedad de la fiebre amarilla en Mesoamérica y que las epidemias hayan contribuido a despoblar a algunas ciudades mayas. En este libro, Hunbatz y Hunchouen se convierten en monos ${ }^{4}$.

Las condiciones bioclimáticas en las cuales vivían los antiguos mayas reunieron las condiciones para la transmisión de la fiebre amarilla. La selva era poblada de monos e insectos como los mosquitos. En el mito de creación del Popol Vuh, los dioses crean a los primeros seres humanos de madera, estos son imperfectos y carentes de sentimientos. Luego, son destruidos los primeros seres humanos, los cuales se convierten en monos. El mito registra a los mosquitos como la "fuerza aérea" encargada de atacar ferozmente a los hombres:

Desde allí enviaron a un animal llamado Mosquito: éste debía recoger las noticias que ellos le enviaban a buscar. Y estas eran sus órdenes: "Pica a cada uno de ellos. Muerde primeramente al que esté sentado primero y después acaba por picarlos a todos. Tu alimento será chupar en los caminos la sangre humana. "Muy bien" - respondió Mosquito. Entonces entró por el camino negro. Llegó junto al muñeco labrado en madera, los primeros sentados engalanados. Picó al primero que no habló; picó al otro, picó al segundo sentado que no habló... Picado el sexto, dijo: ¡Ay! - dijo ¿Qué? ¿El de la Ictericia? - le dijo el del Absceso... (citado por Salvador Novo, 1964).

Otros documentos mayas son también muy elocuentes. En los Chilam Balamde Chumayel, de Tizimin y de Kaua, las menciones de xekik (vómito de sangre), permiten determinar la cronología de la aparición de esta enfermedad antes de la llegada de los españoles. La primera fecha de un xekik corresponde al periodo entre 1480 y 1485 . Existe además la referencia que permite situar una epidemia entre 1342 y 1362 que sería la primera que se registrara en América y que consistió en "muertes súbitas, arrebatadas, sin motivo, y vómitos de sangre", que se habían presentado en las ciudades despobladas y de las cuales las profecías anunciaban el regreso (S. Novo, 1964).

En el periodo prehispánico y al principio de la conquista, las enfermedades eran conocidas como cocoliztles por los indígenas náhuatl, término que significaba "enfermedad o pestilencia", los múltiples males fueron sufridos a la vez que observados, estudiados y clasificados por los médicos indígenas. En el siglo XVI nuevas enfermedades epidémicas aparecieron en Mesoamérica. Estas nuevas enfermedades impactaron en las poblaciones indígenas para los que no existía inmunidad alguna, los cambios de modo de vida y la llegada de agentes biológicos fueron el marco propiciatorio. También, la esclavitud, el hambre, la desnutrición, la explotación física y moral, el alcoholismo, entre otros males, se sucedieron a partir de 1521. Las enfermedades epidémicas como la viruela, el sarampión, la parotiditis, el tifo, y la tosferina mataron a un porcentaje elevado de la población nativa. Bernal Díaz del Castillo ${ }^{5}$, menciona en su "Historia verdadera de la Conquista de Nueva España", que la viruela fue la primera enfermedad importada por los españoles en Nueva España por uno de los soldados. En el siglo XVI hubo dos grandes epidemias, la de 1545 y la de 1576, que fueron llamadas hueycocoliztli, es decir la gran enfermedad (E. Malvido, 1985).

Las epidemias y las enfermedades en general en el mundo náhuatleran entendidas en el marco de una concepción mágico-religiosa. Existían dioses "buenos" como Quetzalcóatl, la serpiente verde y emplumada que simbolizaba al "dios de la vida" y dioses "malos" como Tezcatlipoca ("espejo humeante") que personificaba el castigo y la enfermedad, pertenecía al reino de las tinieblas y que atraían la enfermedad y los cataclismos. Existía la concepción de estar "poseído", y se tenía que "sacar" el alma. Los dioses nahuas protectores como Ometeotl tenían el propósito de mantener la vida humana sobre la tierra y fertilizaba la tierra, la diosa madre (Ometeotl tiene su doble complementario) cuidaba el embarazo y el parto y cuidaba a las embarazadas en los temascales (baños de vapor) ${ }^{6}$.

Se relacionaba a Tlaloc (dios del agua) con el edema y la ascitis y se creía que los ahogados y
4. Esto queda como hipótesis ya que no existen evidencias arqueológicas. 5. Fue de hecho escrita por Hernán Cortes, como lo demostró C. Duverger 2013 .

6. Todavía hoy al momento de entrar o salir de un temascal, se debe pronunciar la palabra: Ometeotl. 
las víctimas de un rayo iban al primer cielo inferior, el Tlalocan, la morada de Tlaloc. El pensamiento prehispánico sobre la enfermedad descansaba en la bipolaridad frio-calor, se consideraba que la posesión por seres celestes se manifestaba como una enfermedad "caliente", y la posesión por seres del inframundo producía una enfermedad "fría". Los intermediarios entre los dioses y los hombres, entre lo divino y lo terrenal eran los chamanes que llamaban ticitl o titici (plural de ticitl). Según Frisancho Velarde (2012), "Ios titici-chamanes de Tláloc atendían a los quemados por el rayo, los de Ehécatl a los que padecían enfermedades osteoarticulares, los de Xipe-Tótec a los enfermos de la piel, los de Ixtliton a los niños, los de Tezcatlipoca atendían las epidemias, entre otros".

\section{CONCLUSIONES}

En el mundo prehispánico, encontramos mitos de fundación como verdaderos relatos de la construcción de un pensamiento cíclico en el cual forman parte una serie de destrucciones y renacimientos de eventos catastróficos climáticos o geológicos. Estos mitos son el fundamento de una forma de pensamiento que todavía no se ha acabado; se transforma, se adapta, según las culturas y las zonas geográficas. Podríamos decir que el pensamiento mítico mesoamericano está todavía vivo y aparece de vez en cuando en las fiestas, rituales y acontecimientos religiosos actualesde las poblaciones mestizas.

El mundo mesoamericano era muy inestable, huracanes, sismos, lluvias torrenciales afectaban los cultivos y a las poblaciones. No es casualidad que los grandes mitos (4 soles, diluvios) hayan marcado el pensamiento cosmológico de las poblaciones prehispánicas.Como muchos pueblos del mundo antiguo y de América, los habitantes de Mesoamérica creían que antes de la era actual, se habían sucedido varias épocas que terminaron en cataclismos. Estas tradiciones se mencionan de manera bastante concisa en varias fuentes escritas, principalmente del centro de México.

M. Eliade (1970) dice que el diluvio y el baño ritual de purificación corresponden al mismo símbolo. Parece que, en el campo que nos interesa, no sólo el agua torrencial, sino también el fuego, la tierra y el aire constituyeron agentes de depuración y purificación.La tierra también se estaba purificando. Uno de los ritos más frecuentes era humillarse comiendo tierra (tlalcualiztli). Es un aspecto que todavía queda por explorar que no hemos abordado aquí.

A la llegada de los españoles en el siglo XVI, los mitos fueron poco a poco reemplazados por las creencias cristianas, por lo tanto, a pesar de algunas fuentes (códices) que pudieron salvarse de la destrucción, existen todavía muchas interrogaciones sobre el pensamiento cosmogónico prehispánico.

Finalmente, el tema de los desastres en el mundo prehispánico tendrá que explorarse con más profundidad. Este trabajo es como una introducción al tema, y esperamos que otras investigaciones futuras llenen la falta de conocimientos actuales.

\section{AGRADECIMIENTOS}

Este trabajo forma parte de un trabajo de investigación financiado por la Secretaría de Posgrado e Investigación del Instituto Politécnico Nacional.

\section{Referencias}

Albores, B., Broda, J., (coordinadoras). (2003). Graniceros, cosmovisión y meteorología indígenas de Mesoamérica. El Colegio Mexiquense - UNAM, México.

Cárdenas-Marrufo, M.F., Pech-Sosa, N., Arias-León, J.J. (2017). Fiebre amarilla: una amenaza histórica. Ciencia y Humanismo en la Salud, 4 (3), 97-105. http://revista.medicina.uady.mx

Caso, A. (2018). ¿Religión o religiones mesoamericanas? Estudios de cultura náhuatl, 56, 163-183.

Chilam Balam de Chumayel. (1973). Traducción Antonio Mediz Bolio. UNAM, México.

Covarrubias, M. (1961). El águila, el jaguar y la serpiente, arte indígena americano. UNAM, México.

Cuevas Fernández H. \& Navarrete Hernández M. (2006). Los huracanes en la época prehispánica y en el siglo XVI. En: Inundaciones 2005 en el Estado de Veracruz, Instituto, de antropología de la Universidad Veracruzana, pp.39-49.

Díaz del Castillo, B. (2006). Historia Verdadera de la Conquista de la Nueva España, México. 
Duverger, C. (1979). La fleur létale, économie du sacrifice aztèque. Seuil, Paris.

Duverger, C. (1983). L'origine des Aztèques. Seuil, Paris.

Duverger, C. (2013). Cortés et son double : enquête sur une mystification. Paris.

Eliade, M. (1970). Traité d'Histoire des Religions. Paris.

Ferradas, P. (2015). Historia mundial de los desastres, la memoria es también porvenir. Soluciones Prácticas, Lima.

Florescano, E. (2004). Quetzalcóatl y los mitos fundadores de Mesoamérica. Taurus, México.

Frisancho Velarde, O. (2012). Concepción mágico-religiosa de la Medicina en la América Prehispánica. Acta Médica Peruana, 29(2), 121-127.

García Acosta, V. (2001). Los sismos en la historia de México, Tomo I \& II. Fondo de Cultura Económica, UNAM y CIESAS, Mexico.

García Acosta, V. (2018). ¿Los temblores tienen un origen divino o natural? Arqueologia mexicana, 25(149), 64-69.

García Barrios, A. (2014). El mito del diluvio en las ceremonias de entronización de los gobernantes mayas. Estudios de Cultura Maya,16, 9-48.

García Icazbalceta, J. (1882). Historia de los Mexicanos por sus pinturas, Anónimo del siglo XVI, Anales del Museo Nacional de México. Num. 2 Tomo II, INAH.

Garza (de la), M. (1978). El hombre en el pensamiento religioso náhuatl y maya. UNAM, México.

Goloubinoff, M., Katz, E. \& Lammel, A., (editoras). (1997). Antropología del clima en el mundo hispanoamericano, Tomo I y II. Ediciones Abya-Yala, Quito.

Graulich, M. (1983). Les ères ou soleils des anciens Mésoaméricains. Indiana, 8, 57-92.

Hermesse, J. (2007). Appropriation de l'environnement naturel par l'ethnie Maya Mam de Quetzaltenango (Guatemala) dans un contexte de mutation des systèmes symboliques et de vulnérabilité aux catastrophes dites naturelles. Territoires et Sociétés dans les Amériques. Rennes, France. https://halshs.archives-ouvertes.fr/halshs-00267480

Histoyre du Méchique. (1905). Manuscrito en francés inédito del siglo XVI. Texto establecido y anotado por E. de Jonghe. Journal de la Société des Americanistes de Paris, 2, 1-42.

Konrad, Herman W. (2003). Ecological Implications for Pre-Hispanic and Contemporary Maya Subsistence on the Yucatan Peninsula. Revista de la Universidad autónoma de Yucatán, 224, 99-126.

Lafaye, J. (1995), Quetzalcoatl y Guadalupe. FCE, México.

Lammel, A., Goloubinoff, M., Katz, E. (editoras). (2008). Aires y Lluvias, antropología del clima en México. CIESAS-IRD, México.

Landa, Fray Diego de. (1966), Relación de las cosas de Yucatán. Porrúa, México.

León-PortillaM. (1958). Siete ensayos sobre cultura náhuatl. Facultad de Filosofía y Letras, UNAM, México.

Le Roy Ladurie, E., Berchtold, J., \& Sermain, J-P. (2007). L'évènement climatique et ses représentations (XVIIe-XIXe siècle). Desjonquières, Paris.

López Austin, A. (2009). “El dios en el cuerpo”. Dimensión Antropológica, 7-45.

Novo, S. (1964). Breve historia y antología sobre la fiebre amarilla. Prensa médica Mexicana, México.

Ortiz, F. (1947). El huracán, su mitología y sus símbolos. FCE, México.

Popol Vuh, (1968). Las antiguas historias del Quiché. FCE, México.

Rojas Aceval, S. (1991). Comportamiento sísmico de edificios prehispánicos en Mesoamérica. Cuadernos de arquitectura, 15, 57-65.

Stuart, D. (2005). The Inscriptions from Temple XIX at Palenque. A Commentary. The Pre-Columbian Art Research Institute, San Francisco.

Velásquez García. (2006). El mito maya del diluvio yla decapitación del caimán cósmico. Instituto de Investigaciones Estéticas, UNAM, Publicaciones Electrónicas de P.A.R.I., México. 